\title{
A Multifactorial Diet in the Management of Hyperlipidaemia
}

\author{
S. Choudhury, P. Jackson, M.B. Katan, C.B. Marenah, C. Cortese, \\ N.E. Miller and B. Lewis \\ Department of Chemical Pathology and Metabolic Disorders, St. Thomas' Hospital Medical School, \\ London, SE1 TEH (Great Britain) \\ (Received 7 July, 1983) \\ (Revised, received 1 August, 1983) \\ (Accepted 1 August, 1983)
}

\section{Summary}

To augment the effectiveness of conventional lipid-lowering treatment, a diet has been evolved combining modified fat content with an increase in vegetable-derived fibre and protein. This was evaluated in 37 hyperlipidaemic and normal ambulant subjects in whom plasma lipid and lipoprotein responses were measured for 4.7-11 months. Mean reductions in plasma cholesterol, triglyceride and low density lipoprotein cholesterol levels were 22,24 and $25 \%$ respectively; there was no significant change in the cholesterol concentrations in high density lipoprotein or in its $\mathrm{HDL}_{2}$ subclass. The effectiveness of the diet in reducing hyperlipidaemia, its influence in optimizing the distribution of cholesterol between plasma lipoprotein classes, and its nutrient composition suggest that it is an advance on existing lipid-lowering dietary patterns.

Key words: Cholesterol - Diet - Hyperlipidaemia - Lipoproteins - Triglyceride

\section{Introduction}

Plasma cholesterol levels are influenced by a number of nutrients including the amount and type of fat, fibre and protein and the intake of cholesterol [1-6]. Each of these effects has been used in the treatment of primary hyperlipidaemia. A

\footnotetext{
Reprint requests should be addressed to B. Lewis.

M.B. Katan is an Established Investigator of the Netherlands Heart Foundation.
} 
fat-modified diet is most widely employed for this purpose, reducing plasma cholesterol by $5-16 \%$ and plasma triglyceride by $12-35 \%[2,7-10]$. We have attempted to identify diets of enhanced effectiveness in reducing plasma lipid levels [11]. In a controlled institutional feeding experiment employing normal men, the two diets most effective in reducing cholesterol levels were those in which multiple dietary changes were made. It appeared that changes in fat and fibre intake, and possibly in protein type, exerted additive effects on plasma cholesterol concentration [11]. One such combination reduced low density lipoprotein (LDL) concentration by 34.5\%. An earlier study, also on normal subjects, may similarly be interpreted as indicating additive effects of these nutrients on plasma cholesterol [12].

One incentive in seeking a lipid-lowering diet of increased effectiveness is the acceptance by many investigators that optimal plasma cholesterol levels are considerably lower than those traditionally assumed [13,14]. A WHO report [13] and a multidisciplinary workshop [14] have considered population means of $5.2 \mathrm{mmol} / 1$ and $4.7 \mathrm{mmol} / \mathrm{l}$, respectively, to be desirable.

A suitable diet would not only reduce total levels of lipids in plasma but would also modify concentrations of individual lipoprotein classes in the direction of reduced cardiovascular risk $[15,16]$. Preferably it should also have characteristics conforming with the growing body of knowledge concerning nutrition and noncardiovascular disease, notably cancer $[17,18]$; though it is probably premature to advocate dietary changes specifically for reduction of cancer risk, it would be inappropriate to design a diet for widespread use that did not take this information into account.

The present study was undertaken with these considerations in mind. The effects of a multifactorial diet (based on the findings in our institutional study) on plasma lipids and lipoproteins were investigated. Ambulant hyperlipidaemic and normal subjects followed an isocaloric or hypocaloric version of the diet for a mean period
of 7.5 months.

\section{Patients and Methods}

Thirty-seven subjects participated; 31 were hyperlipidaemic and 6 had cholesterol levels $<6.5 \mathrm{mmol} / 1$ and triglyceride levels $<2.1 \mathrm{mmol} / 1$. The hyperlipidaemic subjects were recruited from referrals to a lipid clinic over a period of one year, tional reasons), those ale unable to accept dietary management (mostly for occupawas clinical or laboratory eviden or other treatment, and those in whom there mellitus, hepatic or renal diabetes attend the clinic sufficiently frequently was a furt or hypothyroidism). Ability to $>18$ years. The other 6 subjects were lean a further selection criterion, as was age were consuming a typical British diet prior to thembers of the hospital staff who years (mean, 48 years); there were 7 prior to the study. The age range was 21-62 the clinic full clinical examination 7 women and 30 men. At the first attendance at blood glucose and renal and hepatic was performed, a resting ECG recorded, and was measured if indicated; exercise function tests were measured. Serum thyroxine 
carried out if clinically appropriate. Six had coronary heart disease and 2 peripheral vascular disease. Three subjects were hypertensive and were controlled prior to and during the study with propranolol, atenolol or in one patient hydralazine and Moduretic. There were no other relevant clinical problems, and no other drugs were regularly used.

Of the 31 hyperlipidaemic subjects 10 had weight-for-height in the overweight or obese range [19]. The lipoprotein type was IIa in 16, IIb in 11, III in 1 and IV in 3.

Plasma lipids and lipoproteins were measured on venous blood, obtained without prolonged stasis after an overnight fast of 12-14 h. Cholesterol and triglyceride were assayed enzymatically in plasma and in lipoprotein fractions (Boehringer-Mannheim procedures, 187313 and 16448). Very low density lipoprotein (VLDL) was isolated by preparative ultracentrifugation [20]. High density lipoprotein (HDL) was isolated after precipitation of VLDL and LDL by $\mathrm{MnCl}_{2}$ and heparin [21], excess $\mathrm{Mn}$ being chelated by $\mathrm{Na}_{2}$ EDTA prior to cholesterol assay. LDL cholesterol was calculated as the difference between concentrations of cholesterol in plasma and the sum of VLDL and HDL cholesterol. The $\mathrm{HDL}_{2}$ subclass was isolated for cholesterol measurement from an aliquot of the heparin-manganese supernatant by ultracentrifugation at a density of $1.125 \mathrm{~g} / \mathrm{ml}$ [22].

Quality control was based on the use of Precilip and Precilip EL (BoehringerMannheim). Mean between-batch coefficients of variation for cholesterol were 3.6\% at $8.9 \mathrm{mmol} / 1$ and $2.8 \%$ at $2.5 \mathrm{mmol} / 1$; for triglyceride they were $2.8 \%$ at 3.2 $\mathrm{mmol} / 1$ and $3.0 \%$ at $1.8 \mathrm{mmol} / \mathrm{l}$.

During and for at least 8 weeks prior to the baseline observations participants consumed their habitual diet. Baseline lipid and lipoprotein measurements were obtained on two occasions after recruitment, at an interval of 2 or 3 weeks, during which body weight did not change by more than $\pm 1 \mathrm{~kg}$. The mean cholesterol and triglyceride levels did not change significantly between the first and second baseline samples. Subjects were then instructed by the dietitian (P.J.), the interview lasting for 30-40 min. No patient declined dietary treatment. Habitual food preferences and approximate energy intake were noted and taken into account in prescribing the modified diet.

The qualitative changes in diet comprised increased consumption of foods of vegetable origin providing complex carbohydrate, fibre including pectins, and protein, with emphasis on pulses, leafy and root vegetables, fruit, bread and cereals (particularly whole grain varieties); fish, lean meat and poultry and skimmed milk and its products were included, while fatty meats, high fat dairy products and commercial baked goods were severely restricted. A moderate allowance of linoleic acid-rich oils and margarine based on such oils was made. A maximum alcohol intake of 2 drinks per day (approximately $18 \mathrm{~g}$ ) was specified. In overweight subjects an energy intake of $1500 \mathrm{kcal} /$ day was prescribed, while participants whose weightfor-height was in the acceptable range received an isocaloric diet in the range 1500-3000 kcals. The nutrient content of the recommended diet (Table 1) was calculated from standard U.K. food composition tables [23] and from the pectin (i.e. polygalacturonic acid) contents measured in foodstuffs in the Netherlands [24]. Subjects were provided with a printed diet sheet, recipe leaflets, suggestions on menu 
TABLE 1

NUTRIENT COMPOSITION OF RECOMMENDED DIET, COMPARED WITH NATIONAL FOOD SURVEY MEAN ESTIMATES AND WITH CONVENTIONAL LIPID-LOWERING DIET

\begin{tabular}{|c|c|c|c|}
\hline$\therefore$ & Study diet & NFS (1978) ${ }^{a}$ & $\begin{array}{l}\text { Lipid-lowering } \\
\text { diet }\end{array}$ \\
\hline Protein (\% energy) & 16 & 13 & $14-18$ \\
\hline Vegetable protein (\% energy) & 8 & 4 & $4-6$ \\
\hline Fat (\% energy) & 27 & 42 & $30-35$ \\
\hline \multicolumn{4}{|l|}{ Polyunsaturated } \\
\hline fatty acids ( $\%$ energy) & 8 & 4 & 10 \\
\hline Dietary fibre $(\mathrm{g} / 2000 \mathrm{kcal})$ & 52 & 20 & 22 \\
\hline \multicolumn{4}{|l|}{ Pectin $(\mathrm{g} / 2000 \mathrm{kcal}$ as poly- } \\
\hline galacturonic acid) & 7.2 & 3.1 & 3.1 \\
\hline Cholesterol $(\mathrm{mg} / 2000 \mathrm{kcal})$ & 200 & $405^{b}$ & $250^{b}$ \\
\hline Potassium $(\mathrm{mmol} / \mathrm{d})$ & 135 & 77 & \\
\hline Beta-carotene (mg/d) & 8.2 & 2.4 & \\
\hline Ascorbic acid (mg/dl) & 208 & 54 & \\
\hline
\end{tabular}

a Reference [25].

b $\mathrm{mg} /$ day.

adaptations and suggestions for packed lunches when the midday meal was taken away from home. A sample days menu is shown in Table 2 with, for comparison, a conventional fät-modified diet.

Participants were seen by the dietitian on follow-up at 4 weeks and, if ap-

TABLE 2

A TYPICAL MENU Fö́ THE MULTIFACTORIAL DIET AND FOR A CONVENTIONAL FAT-MODIFIED DIET

\begin{tabular}{|c|c|c|}
\hline & Multifactorial diet & Fat-modified diet \\
\hline Breakfast & $\begin{array}{l}\text { muesli with dried fruit } \\
\text { and skimmed milk } \\
\text { whole meal toast, marmalade }\end{array}$ & $\begin{array}{l}\text { fruit juice } \\
\text { lean grilled bacon, tomato } \\
\text { toast, specified margarine, } \\
\text { marmalade }\end{array}$ \\
\hline Packed lunch & $\begin{array}{l}\text { wholemeal tuna and cucumber sandwich } \\
\text { with specified margarine } \\
\text { wholemeal banana sandwich } \\
\text { fresh fruit }\end{array}$ & $\begin{array}{l}\text { chicken sandwich with specified } \\
\text { margarine } \\
\text { yoghurt }\end{array}$ \\
\hline Dinner & $\begin{array}{l}\text { chili con carne, vegetables, } \\
\text { jacket potato } \\
\text { salad with corn oil dressing } \\
\text { baked apple. }\end{array}$ & $\begin{array}{l}\text { lean roast beef with vegetables } \\
\text { potatoes roasted in corn oil } \\
\text { rice pudding made with skimmed } \\
\text { milk }\end{array}$ \\
\hline Bedtime & $\begin{array}{l}\text { wholemeal tomato sandwich } \\
\text { fresh fruit }\end{array}$ & lean ham sandwich \\
\hline
\end{tabular}


propriate, at 8 weeks. One to three 48 -h food diaries were kept by the subjects in the first 4 weeks to assess understanding of and compliance with the diet; from these an estimate of actual nutrient intake was made. Compliance was encouraged. Dietary adjustments were sometimes made because of inappropriate weight trends, hunger or satiety. It was calculated that a mean of $16 \%$ energy was derived from protein, of which $40 \%$ was from vegetable sources (31\% in the U.K. National Food Survey of 1978) [25]. Fats provided 28\% of energy, range 22-33\% (42\% in National Food Survey) with a ratio of polyunsaturated fatty acids to saturated fatty acids ( $P: S$ ratio) 0.6-1.2; pectin intake averaged $5 \mathrm{~g}$ /day (range 3.5-7 g/day), less than recommended, but exceeding the National Food Survey mean of $3.1 \mathrm{~g} /$ day.

Statistical analyses were by the paired $t$-test.
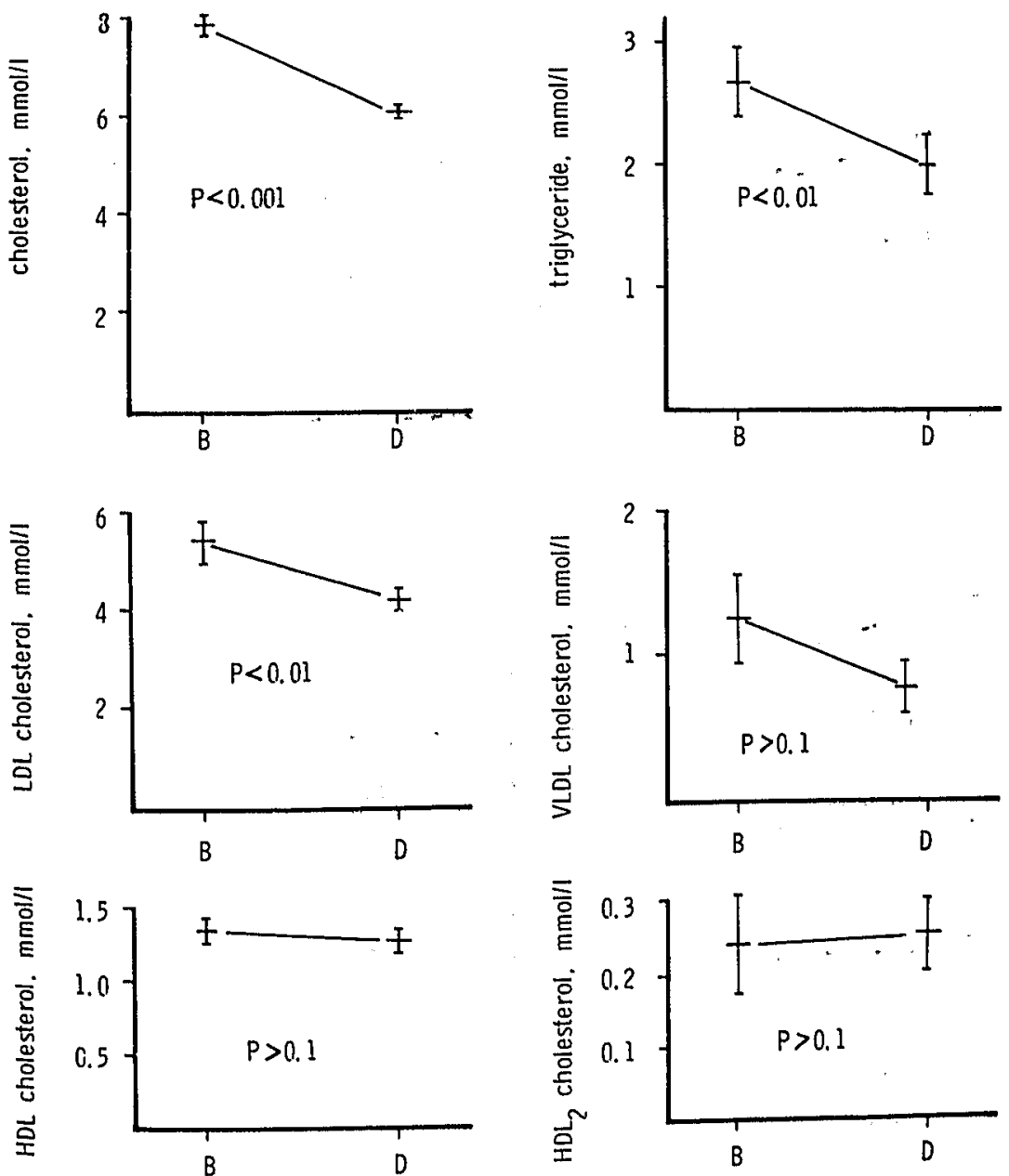

Fig. 1. Response of plasma lipids and lipoproteins to isocaloric diet in hyperlipidaemic subjects. $\mathrm{B}=$ baseline, $\mathrm{D}=$ diet. 


\section{Results}

The response of plasma lipid and lipoprotein concentrations to the modified diet was in most respects similar in the 3 groups. The mean reduction in plasma cholesterol was $22 \%$ and that in triglyceride $24 \%(P<0.001$ in each case). LDL cholesterol fell $25 \%(P<0.001)$, VLDL cholesterol and triglyceride by $37 \%$ and $28 \%$, respectively ( $P<0.05$ for both); there was a $4 \%$ decrease in HDL cholesterol and the cholesterol content of the $\mathrm{HDL}_{2}$ subclass fell by $1.5 \%$ (neither statistically significant).

In its isocaloric form the diet was followed by 21 initially-lean hyperlipidaemic subjects (whose lipid and lipoprotein changes are shown in Fig. 1) and by 6 normal subjects (Fig. 2). The lipid and lipoprotein response of the 10 overweight hyperlipidaemic subjects to the $1500 \mathrm{kcal}$ version of the modified diet is shown in Fig. 3;
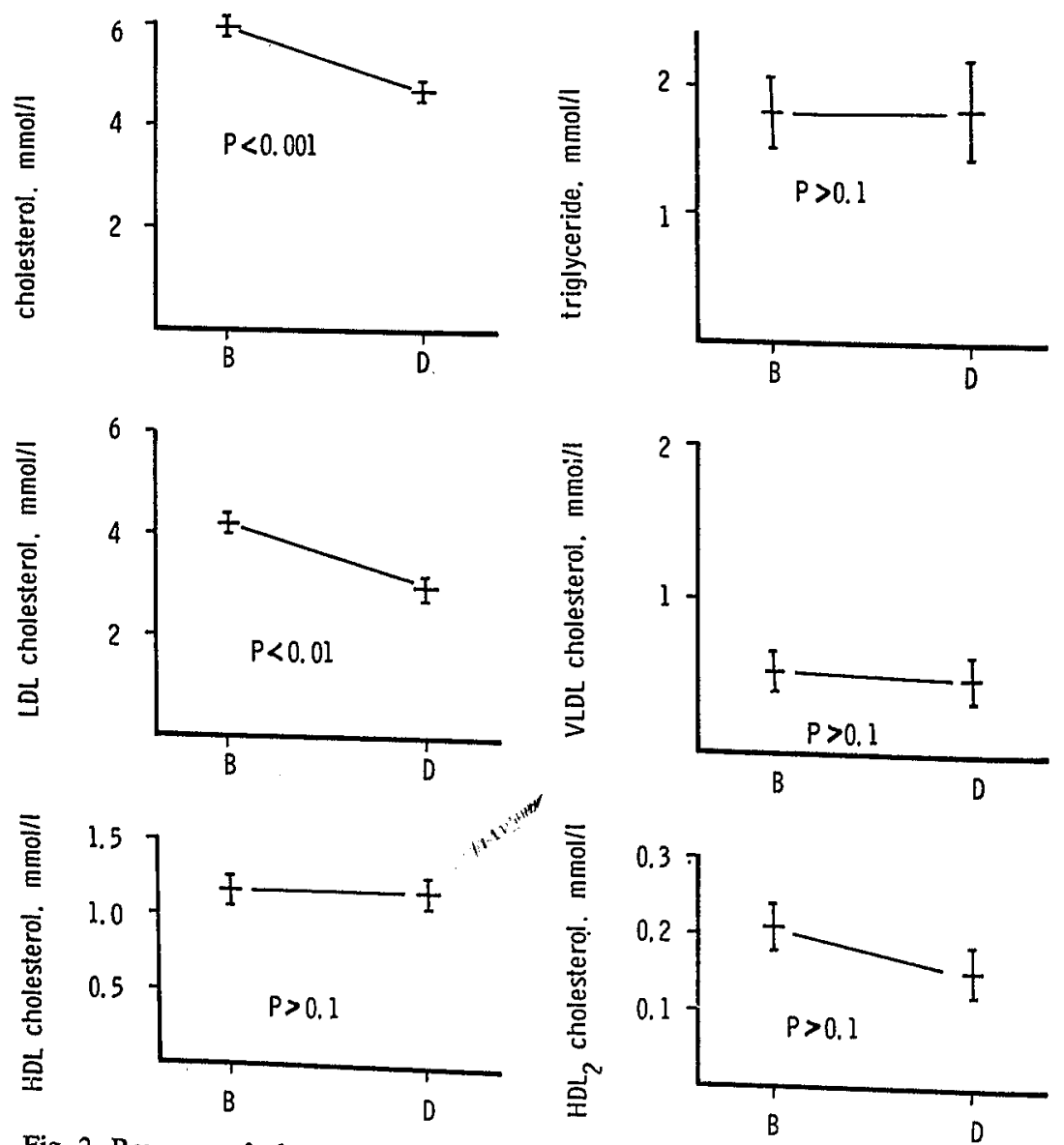

Fig. 2. Response of plasma lipids and lipoproteins to isocaloric diet in normal subjects. $B=$ baseline
$\mathrm{D}=$ diet. 
in this group the mean weight change was $-2.8 \mathrm{~kg}$ (range -6 to $+1 \mathrm{~kg}$ ). The main difference between the groups was the greater reduction in plasma triglyceride and VLDL triglyceride in the overweight subjects receiving a hypocaloric diet (among whom the Type IIb lipoprotein pattern was commoner than in lean subjects), compared with the response to the isocaloric diet. The reductions in plasma cholesterol and LDL cholesterol levels were statistically significant in each group (Figs. 1-3). Hyperlipidaemic subjects showed significant changes in plasma triglyceride, but the fall in VLDL triglyceride was significant only in the hypocaloric
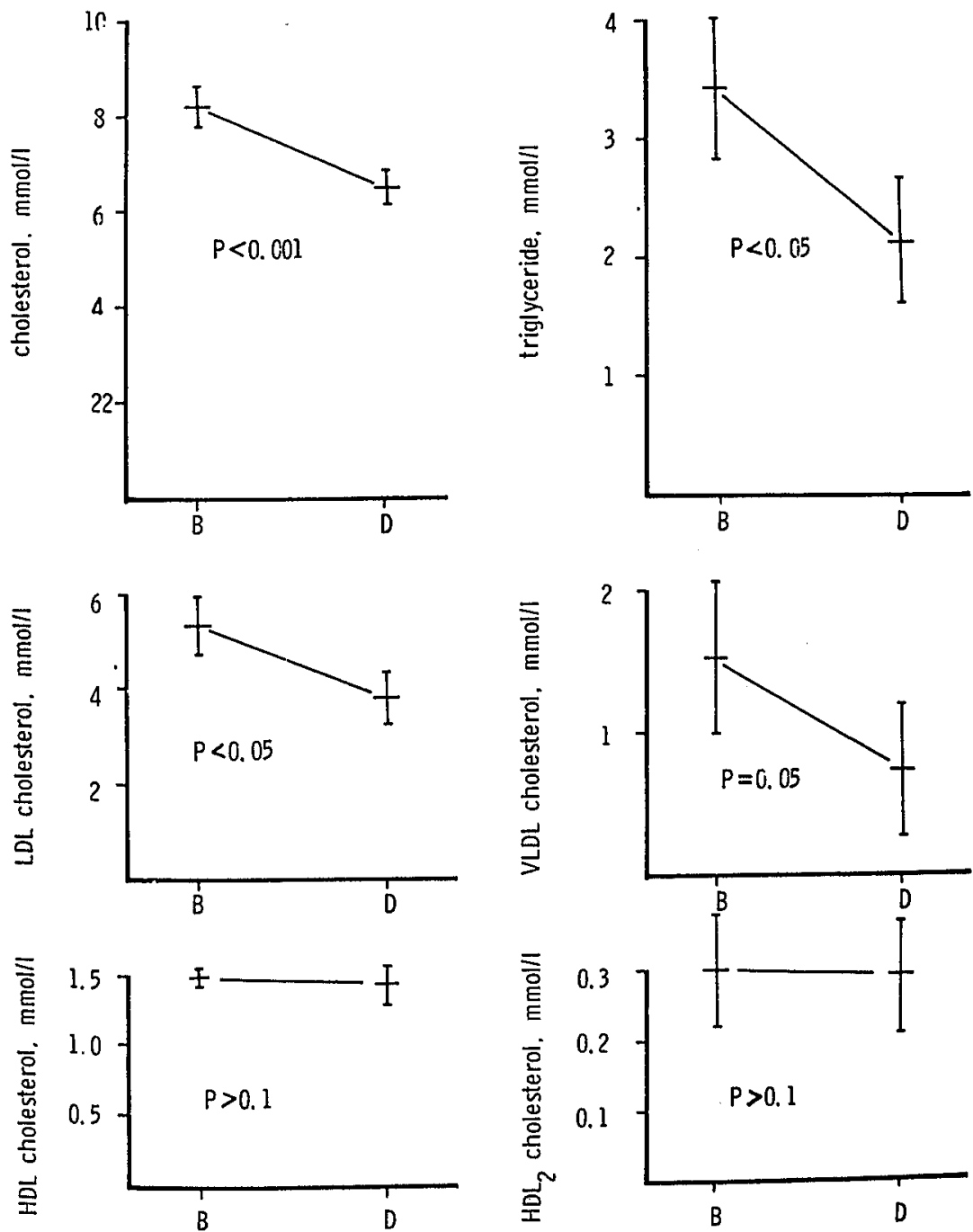

Fig. 3. Response of plasma lipids and lipoproteins to hypocaloric diet in hyperlipidaemic obese subjects. $\mathrm{B}=$ baseline, $\mathrm{D}=$ diet. 
diet group. In no group, nor in the pooled data, were changes in HDL cholesterol or $\mathrm{HDL}_{2}$ cholesterol statistically significant.

The ratio of plasma cholesterol to HDL cholesterol was reduced by $19 \%$ from 5.7 to 4,6 , and that of $\mathrm{LDL}$ cholesterol to $\mathrm{HDL}_{2}$ cholesterol fell by $22 \%$, from 20.7 to 16.2.

\section{Discussion}

The present study concerns the effects of modifying a Western diet on plasma lipids in ambulant hyperlipidaemic and normal subjects. It is an extension of our institutional trial in which 3 lipid-lowering diets were compared in normal subjects during 5-week feeding periods, and in which evidence was obtained of additive interactions between nutrient changes that individually reduce plasma cholesterol levels [11]. In particular the lipid reduction resulting from altering dietary fat intake was enhanced by addition of vegetables and fruit; this was attributable to the known effects of pectin and other dietary fibres on cholesterol metabolism [4,26,27], and possibly also to an increase in the ratio of vegetable-derived protein to protein of animal origin which has been reported to reduce plasma cholesterol in some $[6,28]$ but not all [29] studies.

This principle of additive effects between nutrient changes was applied in the present trial. Differences from the initial study included the longer duration (4.7-11 months), the elevated plasma lipid levels in 31 of the participants, and the free-living conditions which introduced dietary compliance as a further variable. In the present study the diet was a general one including meat and fish, and a moderate intake of alcohol was permitted; the institutional study diets were ovo-lacto-vegetarian in conformity with Trappist rules.

The reduction in plasma cholesterol in the 37 participants in the current study was $22 \%$; this response in free-living subjects over a mean period of 7.5 months is considerably greater than the change of cholesterol level in most comparable trials of a simple fat-modified diet $[1,2,7-10]$.

The fall in cholesterol and triglyceride levels was chiefly attributable to a decrease in LDL and VLDL lipids. The reductions in mean HDL- and $\mathrm{HDL}_{2}$ cholesterol were slight and statistically non-significant, contrasting with the larger decrease in HDL cholesterol when plasma lipid levels were reduced by a large increase in the $\mathrm{P}: \mathrm{S}$ ratio of dietary fats $[30,31]$.

The pattern of food intake in the present study was acceptable to the majority of participants; on the basis of interviews with the dietitian, questioning by the medical staff of the lipid clinic and 48-h food diaries kept by the participants, 32 of the 37 subjects were judged to show good compliance. This may be attributed to the use of foods habitually consumed and freely available in the U.K., and to the use of multiple moderate changes in nutrient intake rather than a radical alteration in any single dietary component. The main change from conventional eating patterns and from the usual fat-modified lipid-lowering diet was the increased proportion of other major difference from a typical British diet. 
The present multifactorial diet may therefore represent an advance on purely lipid-modified regimes towards a diet optimal in respect of plasma cholesterol reduction and of the distribution of cholesterol between the classes of plasma lipoproteins.

The safety of the nutrient intakes characterising this diet requires consideration, as does that of the consequent reduction of plasma cholesterol by 22\%. In previously healthy men with cholesterol levels in the upper tertile, substantial plasma lipid reduction appears to result in reduction of the incidence of and mortality from myocardial infarction $[7,8,16]$; in hyperlipidaemic men with symptomatic peripheral atherosclerosis, a controlled trial has suggested that progression of the disease is considerably retarded by effective treatment of the hyperlipidaemia [32]. As shown in Table 1, the diet provides a moderately reduced intake of fat and increased intakes of beta-carotene, ascorbic acid and fibre. It reduces faecal bile acid concentration [11]. These characteristics offer some reassurance as to potential effects on non-cardiovascular disease risk: epidemiological and experimental data from a number of sources have linked high-fat consumption with promotion of cancers of the breast, colon and other common sites [17,18,33-39] and have suggested that retinoids [40-42] and ascorbic acid [43-45] may protect against certain cancers. Some longitudinal surveys have suggested that low plasma cholesterol is predictive of increased cancer mortality in males [46]. This is not observed within other populations [47] and the time course of the relationship favours the interpretation that low cholesterol levels may be the consequence of early cancer, or of a precursor lesion, rather than its cause [48]. A hypothesis that low cholesterol levels lead to pathological consequences due to altered fluidity of plasma membrane has not been born out by a direct study [49].

\section{Acknowledgements}

We acknowledge with thanks expert assistance by Ms Agnes La Ville and Ms Munira Sheikh.

\section{References}

1 Keys, A., Anderson, J.T. and Grande, E., Serum cholesterol response to changes in the diet, Metabolism, 14 (1965) 747, 759, 776.

2 Lewis, B., The Hyperlipidaemias - Clinical and Laboratory Practice, Chapter 8, Blackwell Scientific Publ., Oxford, 1976.

3 Grundy, S.M., Dietary fats and sterols. In R.I. Levy, B.M. Rifkind, B.H. Dennis and N.D. Ennst (Eds.), Raven Press, New York, 1979, pp. 89-118.

4 Zilversmit, D.B., Dietary fiber, Ibid., p. 149-174.

5 Brussaard, J.H., Dallinga-Thie, G., Groot, P.H.E. and Katan, M.B., Effects of amount and type of dietary fat on serum lipids, lipoproteins and apolipoproteins in man, Atherosclerosis, 36 (1980) 515.

6 Sirtori, C., Agradi, E., Conti, F., Mantero, O. and Gatti, E., Soybean-protein diet in the treatment of type-II hyperlipoproteinaemia, Lancet, i (1977) 275.

7 Mann, J.I. and Marr, J.W., Coronary heart disease prevention - Trials of diets to control hyperlipidaemia. In: N.E. Miller and B. Lewis (Eds.), Lipoproteins, Atherosclerosis and Coronary Heart Disease, Elsevier, Amsterdam, 1981, pp. 197-210. 
8 Hjerrman, I., Velve, Byre, K., Holme, I. and Leren, P., Effect of diet and smoking intervention on the incidence of coronary heart disease, Lancet, ii (1981) 1303.

9 Multiple Risk Factor Intervention Trial Research Group, Multiple risk factor intervention trial, J. Amer. Med. Ass., 248 (1982) 1465.

10 Jones, D.B., Lousley, S., Slaughter, P., Carter, R.D. and Mann, J.I., Prudent diet - Effect on moderately severe hyperlipidaemia, Brit. Med. J., 284 (1982) 1233.

11 Lewis, B., Hammett, F., Katan, M.B., Kay, R.M., Merkx, I., Nobels, A., Miller, N.E. and Swan, A.V., Towards an improved lipid-lowering diet - Additive effects of changes in nutrient intake, Lancet, ii (1981) 1310.

12 Anderson, J.T., Grande, F. and Keys, A., Cholesterol lowering diets, J. Amer. Diet. Ass., 62 (1973) 133.

13 WHO Expert Committee, Prevention of Coronary Heart Disease, World Health Organization, Geneva, 1982.

14 Blackburn, H., Lewis, B. and Wissler, R.W. (Chairmen), Conference on Health Effects of Blood Lipids, Prev. Med., 8 (1979) 612.

15 Gordon, T., Castelli, W.P., Hjortland, M.C., Kannel, W.B. and Dawber, T.R., Predicting coronary heart disease in middle-aged and older persons - The Framingham Study, J. Amer. Med. Ass., 238 (1977) 497.

16 Lewis, B., Ischemic heart disease - The scientific bases for prevention. In: P.N. Yu and J.F. Goodwin (Eds.), Progress in Cardiology, Lea \& Febiger, Philadelphia, 1981, pp. 21-44.

17 Reddy, B.S., Cohen, L.A., McCoy, G.D., Hill, P., Weisburger, J.H. and Wynder, E.L., Nutrition and its relationship to cancer, Adv. Cancer Res., 32 (1980) 238.

18 Doll, R. and Peto, R., The Causes of Cancer, Oxford Medical, Oxford, 1982.

20 Havel, R.J fugally separated H.A. and Bragdon, J.H., The distribution and chemical composition of ultracentrifugally separated lipoproteins in human serum, J. Clin. Invest., 34 (1955) 1345.

21 Albers, J.J., Warnick, G.R., Wiebe, D., King, P., Steiner, P., Smith, L., Breckenridge, C., Chow, A., Kuba, K., Weidman, S., Arnett, H., Wood, P. and Shlagenhaft, A., Multilaboratory comparison of three heparin-Mn $\mathrm{M}^{2+}$ precipitation procedures for estimating cholesterol in high-density lipoprotein,
Clin. Chem., 24 (1978) 853 .

22 Eyre, J., Hammett, F. and Miller, N.E., A micro-method for rapid ultracentrifugal separation of $\mathrm{HDL}_{2}$ and $\mathrm{HDL}_{3}$, Clin. Chim. Acta, 114 (1981) 225.

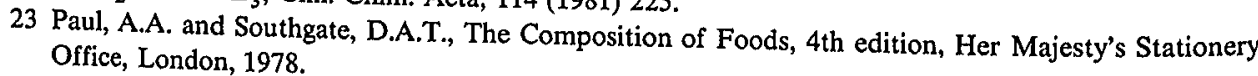

24 Katan, M.B. and Van de Bovenkamp, P., Analysis of total dietary fibre and pectin in Dutch foodstuffs, Voeding, 43 (1982) 153.

25 National Food Survey Committee, Household Food Consumption and Expenditure, 1978. Her Majesty's Stationery Office, London, 1980.

26 Kay, R.M. and Truswell, A.S., Dietary fiber - Effects on plasma and biliary lipids. In: G.A. Spiller Stasse-Wolthuis, Katan, M.B., Brydon, W.G. and East, Van Jeveren, J.G., Wil de Jong, J., Hautvast, J.G., Hermus, R.J., bran or citrus pectin on serum lipids, 1745.

28 Carroll, K.K, Giovannetti, P. cholesterolemic effect of substituting soy-bean., Moase, D., Roberts, D.C. and Wolfe, B.M., Hypowomen, Amer. J. Clin. Nutr., 31 (1978) 1212 protein for animal protein in the diet of healthy young

29 Van Raaij, J.M.A. Katan,

casein, soy isolate, and soy concest, C.E. and Hautvast, J.G.A.J., Influence of diets containing volunteers, Amer. J. Clin. Nutr., 35 (1982) 925 serum cholesterol and lipoproteins in middle-aged

30 Shepherd, J. Packard, C.

polyunsaturated and saturated fat on the propertie, A.M. and Taunton, O.D., Effects of dietary apolipoprotein A-I, J. Clin. Invest., 61 (1978) 158 . 
31 Vessby, B., Boberg, J., Gustafsson, I.-B., Karlström, B., Lithell, H. and Östlund-Linqvist, A.M., Reduction of high density lipoprotein cholesterol and apolipoprotein A-I concentrations by a lipid-lowering diet, Atherosclerosis, 35 (1980) 21.

32 Duffield, R.G.M., Lewis, B., Miller, N.E., Jamieson, C.W., Brunt, I.N.H. and Colchester, A.C.F., Treatment of hyperlipidaemia retards progression of symptomatic femoral atherosclerosis - A randomised controlled trial, Lancet, ii (1983) 639.

33 Newell, G.R. and Ellison, N.M. (Eds.), Nutrition and Cancer - Etiology and Treatment, Raven Press, New York, 1981.

34 Armstrong, B.K. and Doll, R., Environmental factors and cancer incidence and mortality in different countries, with special reference to dietary practices, Int. J. Cancer., 15 (1975) 617.

$35 \mathrm{Liu}$, J., Stamler, J. and Moss, D., Dietary cholesterol, fat, fibre and colon cancer mortality, Lancet, ii (1979) 782.

36 Carroll, K.K., Lipids and carcinogenesis, J. Environ. Path. Toxicol., 3 (1980) 253.

37 Editorial, The link between cholesterol and cancer, Lancet, ii (1980) 243.

38 Phillips, R.L., Role of life-style and dietary habits in risk of cancer among Seventh-day Adventists, Cancer Res., 35 (1975) 3513.

39 Enstrom, J.E., Cancer and total mortality among active Mormons, Cancer, 42 (1978) 1943.

40 Wald, N., Idle, M., Boreham, J. and Bailey, A., Low serum-vitamin-A and subsequent risk of cancer, Lancet, ii (1980) 813.

41 Kark, J.D., Smith, A.H., Switzer, B.R. and Hames, C.G., Serum vitamin A and cancer incidence in Evans County, Georgia, J. Nat. Cancer Inst., 66 (1981) 7.

42 Shekelle, R.B., Lepper, M., Liu, S., Maliza, C., Raynor, W.J., Rossof, A.H., Paul, O., Shryock, A.M. and Stamler, J., Dietary vitamin A and risk of cancer in the Western Electric Study, Lancet, ii (1981) 1186.

43 Correa, P., Haenszel, W., Cuello, C., Tannenbaum, S. and Archer, M., A model for gastric cancer epidemiology, Lancet, ii (1975) 58.

44 Mirvish, S.S., N-nitroso compounds - Their chemical and in-vivo formation and possible importance as environmental carcinogens, J. Toxicol, Environ. Health, 2 (1977) 1267.

45 Weisburger, J.H., Marquardt, H., Hirota, N., Mori, H. and Williams, G.M., Induction of cancer in the glandular stomach of rats by an extract of nitrite-treated fish, J. Nat. Cancer Inst., 64 (1980) 163.

46 Williams, R.R., Sorlie, P.D., Feinleib, M., McNamara, P.M., Kannel, W.B. and Dawber, T.R., Cancer incidence by levels of cholesterol, J. Amer. Med. Ass., 245 (1981) 247.

47 Dyer, A.R., Stamler, J., Paul, O., Shekelle, R.B., Schoenberger, J.A., Berkson, D.M., Lepper, M., Collette, P., Shekelle, S. and Lindberg, H.A., Serum cholesterol and risk of death from cancer and other causes in three Chicago epidemiological studies, J. Chron. Dis., 34 (1981) 249.

48 International Collaborative Group, Circulating cholesterol level and risk of death from cancer in men aged 40 to 69 years, J. Amer. Med. Ass., 248 (1982) 2853.

49 Marenah, C.B., Lewis, B., Hassall, D., La Ville, A., Cortese, C., Mitchell, W.D., Bruckdorfer, K.R., Slavin, B., Miller, N.E., Turner, P.R. and Heduan, E., Hypocholesterolaemia and non-cardiovascular disease - Metabolic studies on subjects with low plasma cholesterol, Brit. Med. J., 286 (1983) 1603. 